showed good coverage across the range of the four concepts. DIF analyses are in progress.

Conclusions: The item banks exhibited good psychometric properties in the general Dutch population. The four Dutch-Flemish PROMIS item banks can be used to develop CATs for measuring physical function, fatigue, pain behavior and pain interference in the Netherlands. Dutch norm scores are presented.

Disclosure of Interest: None declared

DOI: 10.1136/annrheumdis-2017-eular.1247

\section{THU0713 HOW THE VARIATION IN THE LUMBOPELVIC PATTERNS OF MOVEMENT AFFECTS THE NEUROMOTOR CONTROL OF THE BICEPS FEMORIS DURING TRUNK FORWARD BENDING}

M. Sarti ${ }^{1}$, R. Expositor-Rodríguez ${ }^{2}$, R. Borona-Carvajal ${ }^{1}$, M. Ybañez-García $^{3}$, M. Fuster-Ortí ${ }^{4} .{ }^{1}$ Human Anatomy and Embryology, Universidad de Valencia (UVEG); ${ }^{2}$ Inst, for Research on Musculoskeletal Disorders, Catholic University of Valencia; ${ }^{3}$ Rheumatology Section, Pesset Hospital; ${ }^{4}$ Department of Statistics and Operations Research, Universidad de Valencia (UVEG), Valencia, Spain

Background: Trunk forward bending is one of the most common activities in daily living; it is a two-part movement involving the lumbar spine flexion and pelvis rotation at hip joint. The pattern of movement during forward bending was defined as the relative contribution of the lumbar spine to pelvis motion, and was expressed as the ratio between the ranges of lumbar spine motion to pelvis motion (L/P), which, calculated at certain degrees of trunk flexion during the entire movement, provides the lumbo-pelvic rhythm. This is associated with a specific pattern of activation for back and hip extensor muscles which was coined as flexion relaxation phenomenon, observed either in the erector spinae and biceps femoris (BF). It has been shown that in healthy people lumbopelvic pattern of movement for entire flexion varies, showing both lumbar spine dominant and pelvis dominant-patterns of movement.

Objectives: To find out whether the variation in the lumbopelvic pattern of movement (lumbar spine or pelvis dominant) affects the appearance of the relaxation of the BF during trunk forward bending.

Methods: Surface electrodes were applied to the skin on right BF, midway between ischial tuberosity and head of fibula to record EMG during a trunk flexion movement from the upright position. The EMG signal was full-wave rectified and averaged $(40 \mathrm{~ms})$ to produce a linear envelope. An electrogoniometer measured the differential lumbar spine - pelvis sagittal angular displacement during trunk flexion in asymptomatic subjects. Both signals (EMG and degrees) were synchronously and continuously captured during the movement. Ranges of flexion (ROF) for the lumbar spine, pelvis and trunk motion were calculated for the entire movement. The subjects (both sexes) were assigned to group $-L(n=11)$ and group- $P(n=15)$ according to exhibiting lumbar spine and pelvis dominant patterns of movement (average age,24.5 \pm 3 .3years). The myoelectric relaxation (MR) appearance was defined in terms of degrees of flexion where the electrical activity of the BF was less than that in upright posture (EMG basal), at this point the degrees of flexion for the pelvis and spine were determined; and their respective "range of motion" (ROM) was calculated and normalized to range of trunk flexion. One-way MANOVA was used to determine differences in range of flexion at the appearance of the myoelectric relaxation between groups.

Results: ROF for MR of the BF was significantly greater in group-P $(77,3 \% \pm 3,4 \%)$ $(p<0.01)$ than in group- $L(47,8 \% \pm 2,4 \%)$ for the pelvis, whereas ROF for the lumbar spine was significantly greater in group-L $95 \% \pm 1,2 \%(p<0.01)$ than in group- $P$ $40,41 \% \pm 1,7 \%$.

Conclusions: In healthy subjects, differences in lumbopelvic patterns of movement during trunk flexion vary the appearance of the relaxation of the biceps femoris in the range of flexion. Present results show that the variance of the lumbar spine and pelvis Kinematics is associated with the neuromotor control of the biceps femoris.

Acknowledgements: Grants supporting present study: Ref. FIS2001-0070-01, Ref. TIC2001-2786- C02-02, Ref. AP2001-376

Disclosure of Interest: None declared

DOI: 10.1136/annrheumdis-2017-eular.6855

\section{THU0714 INVESTIGATING THE EFFECTS OF HYPERMOBILITY ON BALANCE VARIABLES}

M. Selmani ${ }^{1}$, A. Elvan ${ }^{1}$, B. Akcay ${ }^{1}$, G. Kenar ${ }^{2}$, A.M. Birlik ${ }^{2}$, S. Angin ${ }^{1}$ I.E. Simsek ${ }^{1}$. 'School of Physical Therapy and Rehabilitation, Dokuz Eylul University Institute of Health Sciences; ${ }^{2}$ Department of Internal Medicine, Dokuz Eylul University Faculty of Medicine, Izmir, Turkey

Background: Hypermobility syndrome (HMS) is a clinical syndrome in which the range of motion of the joint is observed above normal ranges without being associated with a rheumatic disease. Excessive joint motion in HMS reduces joint stability and joint position sense and also can cause pain. Decreased muscle tone and tensile forces of the tendons cause decreased locomotor system stiffness and impairment of proprioception mechanisms. These problems in proprioceptive mechanisms can lead to balance-related disorders in individuals with hypermobility syndrome

Objectives: The aim of this study was to investigate the possible effects of hypermobility on balance variables.
Methods: 50 hypermobile ( 5 males and 45 females) volunteers diagnosed with Brighton Scale and 50 healthy (21 males and 29 females) volunteers were included in this cross sectional study. Participants with a score of 4 or over according to the Beighton scale were referred to a rheumatologist and were administered Brighton scale. Participants who were diagnosed by the physician were included in the hypermobile group. The objective balance evaluation was conducted using a balance platform. Evaluation variables were; static balance on single foot, static balance on both feet, limits of stability test and tandem walking. analysis was performed using independent samples t-test.

Results: The mean age was found $21,69 \pm 2,13$ years old for the control group and $20,09 \pm 2,65$ years old for the HMS group. Body Mass Index was found $22,13 \pm 3,54 \mathrm{~kg} / \mathrm{m}^{2}$ in the control group and $21,54 \pm 3,50 \mathrm{~kg} / \mathrm{m}^{2}$ in the HMS group. HMS group showed significant wider step width in tandem walking $(p=0,001)$, significantly longer reaction time $(p=0,23, p=0.030)$, significantly higher endpoint excursion $(p=0.003, p=0,026, p=0,049)$, significant higher mean maximum excursions $(p=0.018)$ (Table 1$)$.

Table 1. Comparison of Groups About Balance Variables

\begin{tabular}{|c|c|c|c|}
\hline & $\begin{array}{l}\text { HMS Group } \\
\text { (Mean } \pm \text { SD) }\end{array}$ & $\begin{array}{l}\text { Control Group } \\
\text { (Mean } \pm \text { SD) }\end{array}$ & $p$ \\
\hline \multicolumn{4}{|l|}{ Tandem Walking } \\
\hline Step-Width (cm) & $6,52 \pm 0,89$ & $7,20 \pm 1.10$ & $0.001^{*}$ \\
\hline \multicolumn{4}{|l|}{ Limits Of Stability } \\
\hline Reaction Time 2 (sec) & $0,91 \pm 0.44$ & $0,72 \pm 0.37$ & $0.023^{*}$ \\
\hline Reaction Time 6 (sec) & $0,78 \pm 0,36$ & $0,64 \pm 0,25$ & $0.030^{*}$ \\
\hline End-Point Excursion 1 ( $\% \mathrm{sec})$ & $86,69 \pm 17,73$ & $73,19 \pm 26,17$ & $0.003^{*}$ \\
\hline End-Point Excursion 4 ( $\% \mathrm{sec})$ & $76,56 \pm 17,36$ & $83,92 \pm 14,91$ & $0.026^{*}$ \\
\hline Maximum Excursion 5 ( $\% \mathrm{sec})$ & $76,54 \pm 18,31$ & $82,69 \pm 11,50$ & $0.049^{*}$ \\
\hline Mean Maximum Excursion ( $\% \mathrm{sec}$ ) & $94,56 \pm 6,51$ & $97,25 \pm 4,29$ & $0.018^{*}$ \\
\hline
\end{tabular}

${ }^{*} \mathrm{p}<0.05$

Conclusions: In this study it was found that hypermobility has significant effects on the stability limits test and tandem walking. In previous studies it was found that hypermobility affects the static balance assessment variables $(1,2)$, but in this study dynamic balance assessment variables were affected.

References:

[1] latridou K, Mandalidis D, Chronopoulos E, Vagenas G, Athanasopoulos S. Static and dynamic body balance following provocation of the visual and vestibular systems in females with and without joint hypermobility syndrome. J Bodyw Mov Ther. 2014 Apr;18(2):159-64. doi: 10.1016/j.jbmt.2013.10.003.

[2] Juul-Kristensen B, Johansen K, Hendriksen P, Melcher P, Sandfeld J, Jensen BR. Girls with generalized joint hypermobility display changed muscle activity and postural sway during static balance tasks. Scand J Rheumatol. 2015 Sep $1: 1-9$.

Disclosure of Interest: None declared

DOI: 10.1136/annrheumdis-2017-eular.6256

\section{THU0715 ESTIMATION OF THE EFFECT OF FOOT ORTHOTICS ON HIP JOINT LOADING FOR RHEUMATOID ARTHRITIS PATIENTS USING MRI-BASED MUSCULOSKELETAL MODELS: A PILOT STUDY}

M.B. Simonsen ${ }^{1}$, K. Næsborg-Andersen ${ }^{2}$, M.R. Kowalski ${ }^{3}$,

K. Hørslev-Petersen ${ }^{4}$, M.S. Andersen ${ }^{1}$. ${ }^{1}$ Department of Mechanical and Manufacturing Engineering, Aalborg University, Aalborg; ${ }^{2}$ Bandagist-Centret A/S, Haderslev; ${ }^{3}$ Department of Rheumatology, Hjørring Hospital, Hjørring; ${ }^{4}$ King Christian 10th Hospital for Rheumatic Diseases, Gråsten, Denmark

Background: Over $85 \%$ of rheumatoid arthritis (RA) patients experience feet and ankle problems during the course of the disease. Persistent foot and ankle problems still occur even after clinical remission is reached [1]. In RA, synovitis, effusion, and eventually erosive arthritis are thought to cause clinically recognizable planovalgus or valgus heel [1]. With the intention to stabilize and align the foot, patient-specific foot orthotics (FO) are commonly prescribed to this patient group. A limitation of the previous literature on FO to treat RA and related diseases is that it has focused exclusively on clinical outcomes of FO such as pain and physical function, while overlooking the biomechanical principles on which the rationales for $\mathrm{FO}$ is based [2]

Objectives: The aim of this study was to investigate the effect of patient-specific FO on hip loading during gait. This was accomplished by developing patientspecific (PS) musculoskeletal models (MS) capable of estimating joint mechanics with and without the FO.

Methods: Four early stage RA patients were recruited for this study. A pair of FO was developed for each patient using a weight bearing casting technique. PS bone geometry was obtained from magnetic resonance imaging (MRI) images and segmented in an image analysis package (Mimics 19, Materialse, Belgium). Motion capture was performed with an eight-camera setup (Qualysis, Sweden) with reflective markers together with three force plates (AMTI, USA) sampling at 100 and $1000 \mathrm{~Hz}$, respectively. The gait trials consisted of two conditions: one with the PS FO and one with a control insole (C). PS MS models of each patient were developed using the AnyBody Modeling System (AnyBody Technology, Denmark), Figure 1A. Muscle attachments were made PS based on the Twente Lower Extremity Model version 2.0 dataset using advanced morphing to customize a generic cadaver-based model with respect to PS morphology 